\title{
Revista de la
}

\section{CEPAL}

Secretario Ejecutivo

Gert Rosenthal

Secretario Ejecutivo Adjunto

Carlos Massad

\section{Director de la Revista}

Aníbal Pinto

Secretario Técnico

Eugenio Lahera

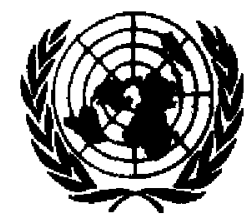

NACIONES UNIDAS

COMISION ECONOMICA PARA AMERICA LATINA Y EL CARIBE SANTIAGO DE CHILE, AGOSTO DE 1992 


\section{Revista de la}

\section{CEPAL}

Santiago de Chile

Agosto de 1992

Número 47

\section{SUMARIO}

Educación y transformación productiva con equidad. Fernando Fajnzylber.

El síndrome del "casillero vacío". P. van Dijck.

La consolidación de la democracia y del desarrollo en Chile. O. Sunkel.

Patrón de desarrollo y medio ambiente en Brasil. R. Guimarães.

Fundamentos y opciones para la integración de hoy. E. Lahera.

Globalización y convergencia: América Latina frente a un mundo en cambio. J.M. Benavente y P. West.

El escenario agrícola mundial en los años noventa. G. Di Girolamo.

La trayectoria rural de América Latina y el Caribe. E. Ortega.

Potencialidades y opciones de la agricultura mexicana. J. López.

La privatización de la telefonía argentina. A. Herrera.

Racionalizando la política social: evaluación y viabilidad. E. Cohen y $R$. Franco.

Economía política del Estado desarrollista en Brasil. J.L. Fiori.

Orientaciones para los colaboradores de la Revista de la CEPAL.

Publicaciones recientes de la CEPAL 
REVISTA DE LA CEPAL N $\mathbf{N}^{0} 47$

\section{El escenario agrícola mundial en los años noventa}

\section{Giovanni Di Girolamo*}

El artículo analiza diversas tendencias internacionales del sector agrícola que guardan relación con el comercio exterior de los países de América Latina. El balance de los años recientes es bastante negativo para la agricultura de los países en desarrollo, tanto desde el punto de vista de la relación de precios del intercambio, como en cuanto a la debilidad de los mercados para sus exportaciones de productos básicos.

Los años futuros serán de intensa competencia en los mercados agrícolas internacionales. Un problema principal del comercio agrícola mundial seguirá siendo la falta de recursos para que la demanda potencial de productos de este sector se convierta cn demanda efectiva.

Diversas proyecciones ponen en tela de juicio que los procesos de apertura fundados principalmente en la inserción en el comercio internacional por la via de los productos agricolas o agroindustriales sean un camino seguro de desarrollo. Los paises exportadores deben diversificar su producción primaria y avanzar hacia un desarrollo agroindustrial que permita la articulación interna de la economia, la modernización de las áreas rurales y la satisfacción de las demandas internas.

* Oficial asociado de Asuntos Fconónicos, División Agricola, CEPAL.

\section{Introducción}

La segunda mitad de los años ochenta se caracterizó por la consolidación de una serie de tendencias desfavorables para el sector agrícola de los países en desarrollo. En los mercados agrícolas internacionales la competencia entre los paises exportadores creció considerablemente, y se acentuaron las tendencias proteccionistas en los países desarrollados. La relación de los precios del intercambio entre los productos agrícolas, por un lado, y los productos manufacturados y el petróleo crudo, por otro, fue empeorando con daño para los primeros a lo largo del período 1980-1988 (gráfico 1). En promedio, en 1988 la relación de precios del intercambio entre productos agrícolas y productos industriales fue inferior en $25 \%$ a la de 1980 . Al mismo tiempo, el saldo propiamente agrícola de los países en desarrollo, considerados en su conjunto, se deterioró bajo la presión simultánea de la caída del valor relativo de sus exportaciones agrícolas y el aumento de las importaciones de productos alimentarios provenientes de los países desarrollados. En Africa, por ejemplo, los ingresos obtenidos por las exportaciones agrícolas en 1989 sólo permitieron a esta región comprar $28 \%$ menos de manufacturas y de petróleo crudo que en 1979-1981. También en América Latina y el Caribe, en el mismo período, el valor total de las exportaciones se redujo, a pesar de haber aumentado considerablemente su volumen.

El empeoramiento del saldo agrícola de los países en desarrollo se puede explicar principalmente por una evolución adversa de los precios de exportación, en particular de los productos alimenticios (gráfico 2). Además, en muchos países en desarrollo que son importadores netos de alimentos se observa una evidente bifurcación entre la tendencia al rápido crecimiento de la población y el aumento relativamente más lento de la producción. En algunos casos, este fenómeno se debe a factores climáticos (en parte de origen atrópico), a la excesiva explotación de la tierra y a situaciones de inestabilidad política local. Sin embargo, la causa principal parece residir en la crisis profunda de la agricultura campesina, inducida por la internacionalización de los mercados agrícolas, por la creciente inestabilidad de los precios y por la falta de capital y capacitación. La crisis de la agricultura campesina genera un circuito perverso: mayores contingentes de la población rural se trasladan a las ciudades; el con- 
Gráfico 1

RELACIONES ENTRE LOS PRECIOS DE LOS PRODUCTOS

AGRICOLAS Y LOS PRECIOS DE LOS PRODUCTOS MANUFACTURADOS

Indice $^{\mathrm{a}}$

(Base: $1985=100)$

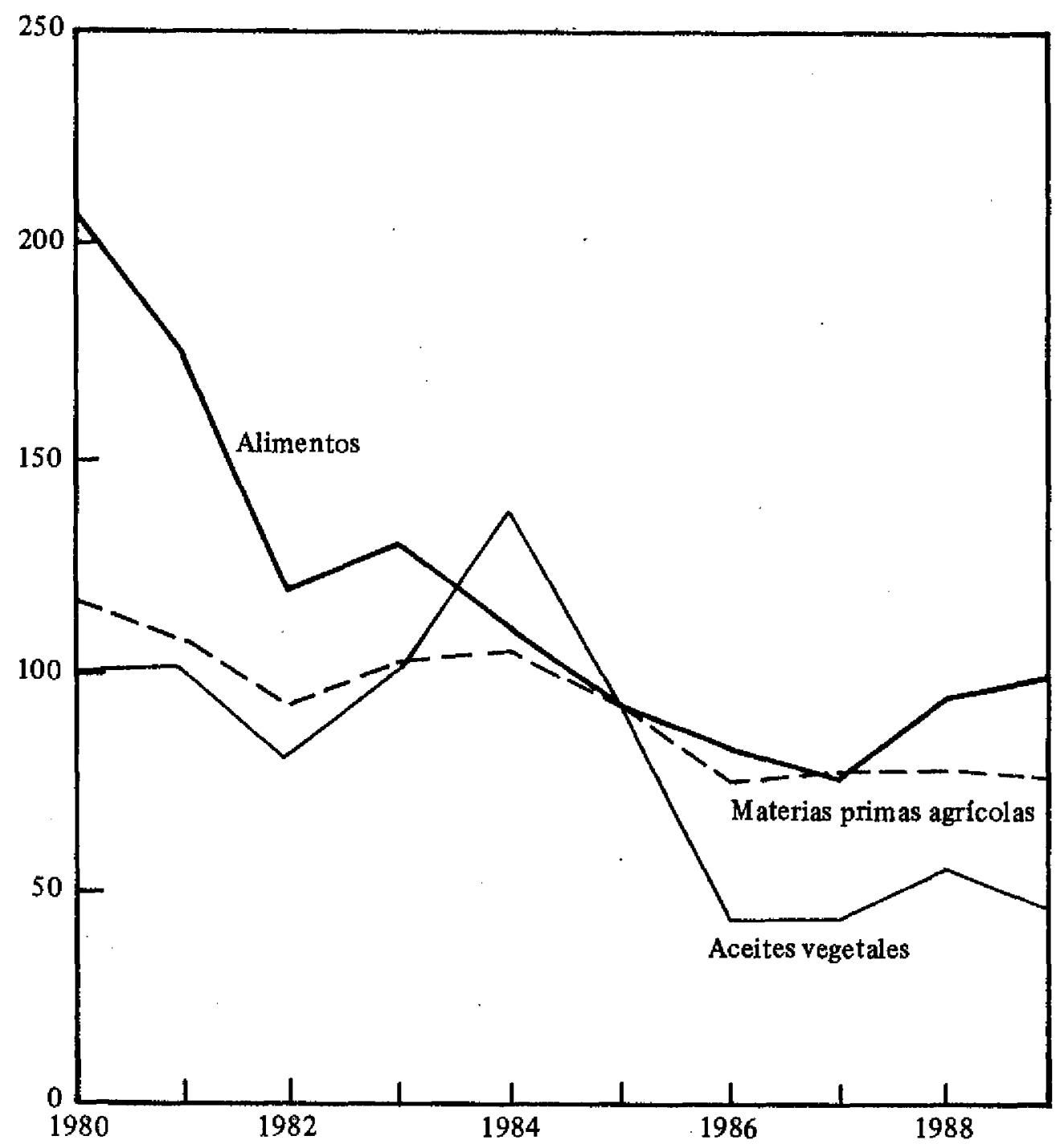

Fuente: Naciones Unidas, Estudio económico mundial, 1990, Nueva York, 1990.

"Indice de precios de los productos agricolas dividido por el índice de precios de los productos manufactureros. 
secuente aumento de las poblaciones urbanas induce a los gobiernos a adoptar políticas agrícolas que tienden a garantizar un bajo precio de los alimentos, por razones de seguridad social ${ }^{1}$, y esto, a su vez, genera un ulterior rezago de la economia campesina y nuevas migraciones. Al mismo tiempo, el país se vuelve deficitario en alimentos y su balanza de pagos empeora.

En la mayoría de los países en desarrollo no exportadores de petróleo el sector agrícola aporta en general entre el 20 y el $40 \%$ del PIB, entre el 60 y el $80 \%$ del empleo y entre el 50 y el $70 \%$ del total de los ingresos por exportación. A pesar de que existen varios casos de desarrollo agroexportador exitosos y prometedores, tanto a nivel de paises como de empresas, los últimos años no han sido particularmente favorables a las exportaciones agropecuarias del sur del mundo. La FAO (1990c) ha calculado que en los 40 países en desarrollo cuyas exportaciones están constituidas principalmente por productos agrícolas, los indicadores macroeconómicos sugieren un panorama general bastante decepcionante en los últimos años. Por ejemplo:

a) El producto interno bruto per cápita disminuyó $1.1 \%$ en 1989 y se estima que en 1990 bajó otro $0.8 \%$. En cambio, en los países en desarrollo con una base de exportación más diversificada, dicho producto aumentó en $1.1 \%$ en 1989 y se estima que en 1990 subió otro $0.2 \%$.

b) En los países en desarrollo que exportan fundamentalmente productos agrícolas, la formación bruta de capital bajó de alrededor del $17 \%$ del PIB en los primeros años del decenio a menos del $14 \%$ en 1989 y 1990 , mientras que en los países en desarrollo con exportaciones más diversificadas el nivel se mantuvo relativamente constante $(20 \%)$. c) En los años ochenta la inflación fue considerablemente más alta en el grupo de países esencialmente agroexportadores que en el de países en desarrollo con exportaciones más diversificadas.

d) Durante la mayor parte del decenio de 1980 los volúmenes de exportación crecieron a un ritmo considerablemente menor en los paises en desarrollo que exportan sobre todo productos agrícolas que en los países exportadores de bienes manufacturados, y la relación de intercambio de los primeros se redujo en casi una tercera parte entre 1985 y 1990.

e) Los volúmenes de importación se redujeron en los países esencialmente agroexportadores en una proporción total de $11 \%$ entre 1982 y 1990 (FAO, 1990C).

Cabe destacar que estos resultados decepcionantes se lograron en un momento de recuperación de la economía mundial, como fue la segunda mitad del decenio de 1980. No parece probable que se logren mejores resultados en el futuro inmediato, cuando se prevé un crecimiento de las economías de los países industrializados menos satisfactorio que en los años pasados.

Por otra parte, los casos más exitosos y más citados de desarrollo agroexportador han tenido lugar en paises con una base exportadora bastante diversificada y no principalmente agrícola. Tailandia, Malasia, Brasil y Chile, por ejemplo, tienen importantes sectores exportadores no agrícolas, ya sea mineros, manufactureros $u$ otros, $y$ además un sector agroindustrial dinámico que ha aprovechado las oportunidades creadas por el desarrollo agroexportador y que está estimulando, a su vez, la demanda interna de productos agrícolas.

\footnotetext{
${ }^{1}$ Actualmente, en alrededor de 100 países en desarrollo una persona de cada cinco está desnutrida. En 1992 se prevén serias crisis alimentarias en Argelia, Etiopia, Liberia, Mozambique y Somalfa.
} 
Gráfico 2

CAMBIOS EN LOS PRECIOS DE EXPORTACION DE LOS PRODUCTOS AGROPECUARIOS $(1980=100)$
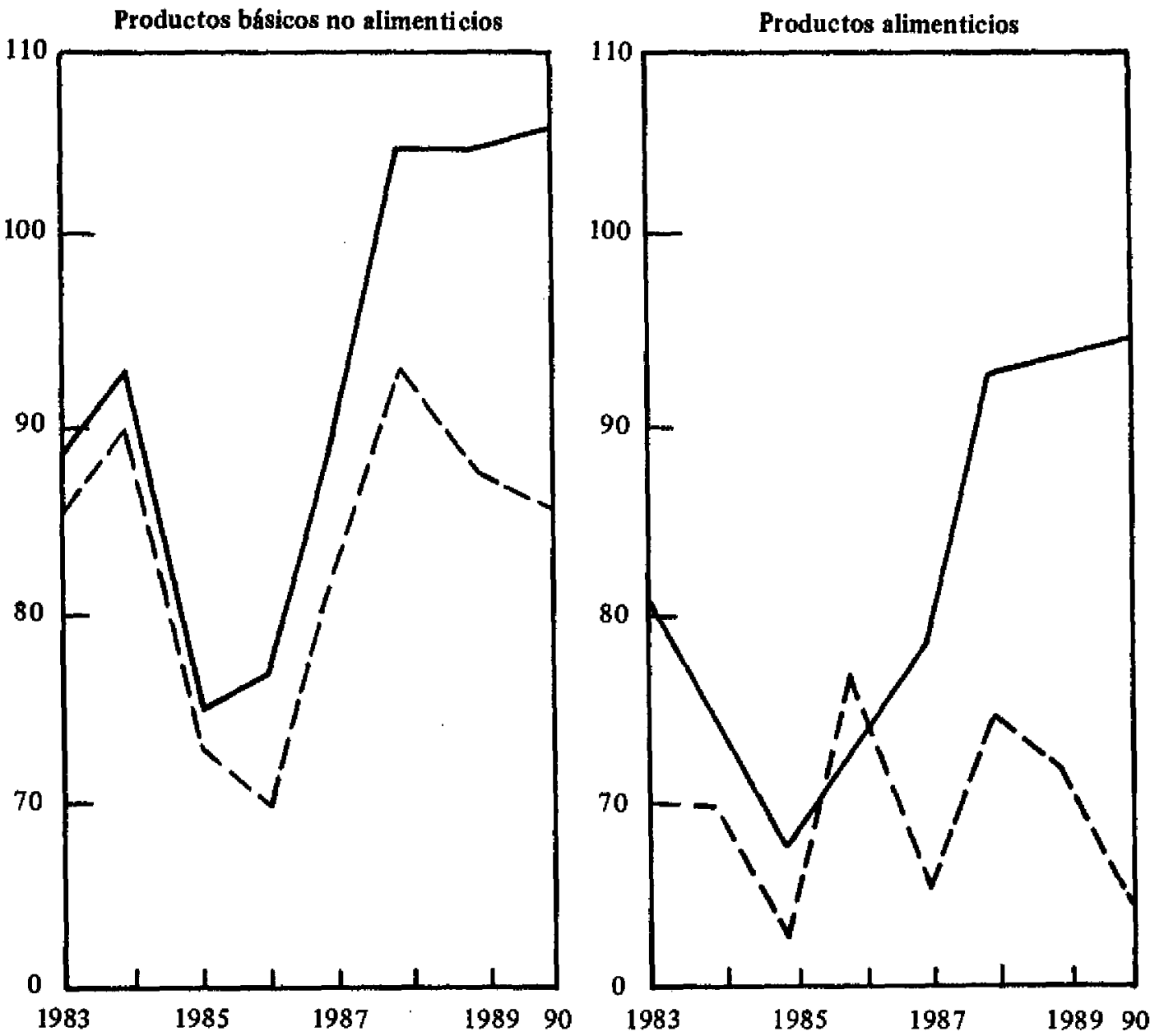

Fuente: Naciones Unidas, Estudio económico mundial, 1990, Nueva York, 1990.

-..-Paises desarrollados 


\section{El caso de América Latina y el Caribe}

\section{La producción}

En América Latina y el Caribe en su conjunto, la producción agrícola creció entre 1981 y 1988 a una tasa media anual de $2.4 \%$, es decir, un poco más que la población. Sin embargo, en 1989 la tasa regional de crecimiento de la producción agrícola bajó al $1.9 \%$, cifra inferior al incremento de la población regional en el mismo año.

Al mismo tiempo, la tendencia secular al decrecimiento de la contribución porcentual de la agricultura al Pı en la región se detuvo a causa de la crisis económica de comienzos del decenio de 1980, e incluso se invirtió durante los años siguientes. (Lo mismo sucedió en Africa, pero no así en los países del Lejano y Cercano Oriente, donde la relación entre el l'IB agrícola y el PIB total se niveló a partir de 1981-1983). La inversión de la tendencia en América Latina y el Caribe confirma la capacidad del sector agrícola de amortiguar las perturbaciones macroeconómicas generales en los periodos de depresión; pero si perdurara en el tiempo, podría señalar el comienzo de un proceso de desindustrialización de la región en su conjunto.

\section{Las exportaciones agricolas}

Entre 1984 y 1989 el valor de las exportaciones mundiales de todo tipo de bienes creció $60 \%$; en el mismo período, el de las exportaciones latinoamericanas subió sólo $8 \%$. La región latinoamericana y caribeña en su conjunto mostró un dinamismo inferior al promedio mundial, $y$ su contribución al valor total de las exportaciones mundiales bajó de $5.8 \%$ en 1984 a $3.9 \%$ en 1989 . En ese año la participación de la región en las exportaciones mundiates fue inferior, en valor, a la de países como Francia ( $5.9 \%$ de las exportaciones mundiales) o el Reino Unido (4.9\%). Este redimensionamiento relativo de las exportaciones regionales se debe, por una parte, al bajo dinamismo de los productos básicos a nivel global, ${ }^{2} y$, por otra, a las dificultades que encuentra

\footnotetext{
${ }^{2}$ Las causas principales del descenso de la participacion relativa de los prodactos primarios en el comercio interna-
}

la región para mejorar su posición relativa en los sectores exportadores más dinámicos. En efecto, en los últimos diez años América Latina no ha podido aumentar su participación relativa en las exportaciones mundiales en ninguna de las seis grandes categorias de bienes y servicios (productos agropecuarios, productos de industrias extractivas, productos manufactureros, transportes, viajes y otros servicios).

En la segunda mitad de los años ochenta las exportaciones mundiales de productos agropecuarios mostraron el mencionado deterioro de la relación de intercambio, y una tasa de crecimiento inferior a la del PrB mundial y, aún más, a la del comercio mundial de toda categoría de productos $^{3}$ (gráfico 3).

Para algunos productos como el café o el cacao, la segunda mitad de los años ochenta fue un período muy negativo: se calcula que en 1989 la caida del precio del café provocó, a nivel mundial, una pérdida en ingresos de más de 1500 millones de dólares. Entre 1989 y 1990 el mercado de este producto se estabiliz6, y a pesar de que el equilibrio existente hoy es bastante precario, es probable que en los próximos años la evolución de la producción influya más en los ingresos de exportación que en períodos anteriores (FAO, 1990b).

Además, en 1989 y 1990 se invirtió la tendencia alcista en los precios de algunos productos, como el trigo, el azúcar y la carne de vacuno,

cional han sido: i) el estancamiento de la demanda global provocada por la desaceleración del crecimiento económico mundial; ii) la generalización creciente de procesos sustitutivos; iii) los progresos técnicos que permiten mayores economias en los procesos de transformación industrial; $y$ iv) la inclinación mayormente protecionista de los paises importaclores. Además, es importante destacar que dentro de una participación declinante en términos relativos de los productos básicos en el comercio internacional, la cuota de exportaciones de productos básicos provenientes de los paises desarrollados fue creciendo en el curso de los años ochenta. Véase cFm, Santiago, 1991.

Finte 1984 y 1989 el valor de las exportaciones mundiales de productos agropecuarios crecio $35.7 \%$, mientras que, como se señató antes, el de las exportaciones mundiales de todos los productos creció $60 \%$. 
Grafico 3

TENDENCIAS DEL COMERCIO MUNDIAL DE PRODUCTOS AGRICOLAS

$Y$ DEL COMERCIO MUNDIAL TOTAL

$(1980=100)$

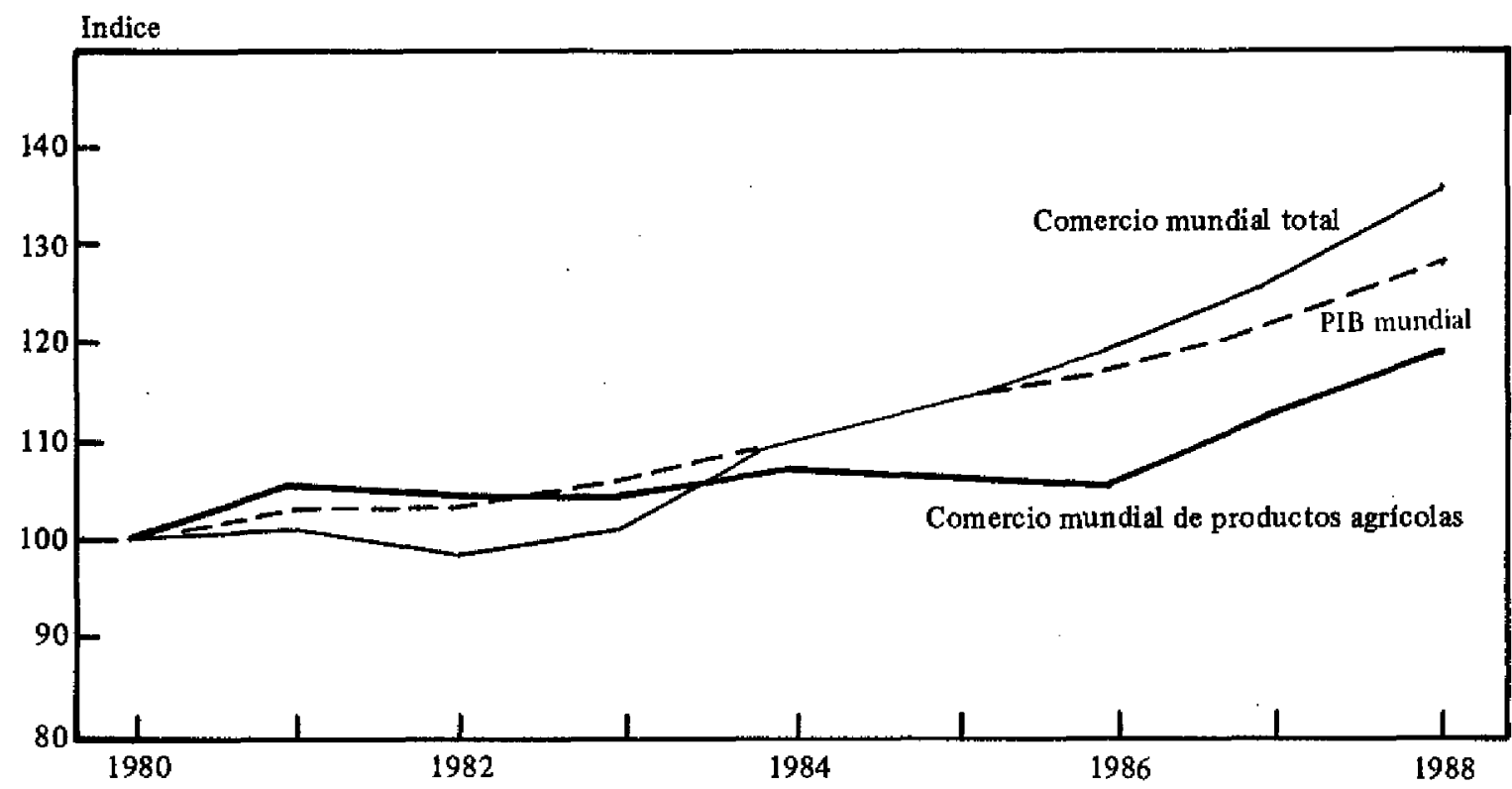

Fuente: GATT, International Trade 1988-1989, Vol. II, Ginebra, 1989.

que había sido relativamente marcada en los años anteriores.

A nivel general, el hecho de que las exportaciones agropecuarias globales hayan crecido a un ritmo inferior al del pus mundial ha significado, lógicamente, un aumento de la cuota de consumo de las producciones internas por parte de los países; es decir, una reducción del índice global importaciones/consumo.

El lento crecimiento de las exportaciones agropecuarias globales, sumado al deterioro de los precios relativos, ha desembocado, a nivel mundial, en una menor participación porcentual de las exportaciones agropecuarias en las exportaciones totales. En efecto, el valor de las exportaciones agropecuarias mundiales, que en 1984 representaba el $11.4 \%$ de las exportaciones mundiales de todo tipo de productos, llegó a representar un $9.6 \%$ en 1989. Dentro de este total reducido, la contribución porcentual de América Latina y el Caribe se contrajo aún más, pasando del $14.4 \%$ en 1984 al $10.5 \%$ en 1989 .

Como se puede ver en el cuadro 1 , entre
1984 y 1989 las exportaciones agropecuarias totales de América Latina no crecieron en valor (más bien experimentaron una reducción de un $0.7 \%$ ), mientras que las exportaciones agropecuarias mundiales aumentaron, principalmente por el incremento de las exportaciones europeas y asiáticas. Factores monetarios (baja del valor del dólar) y de precio (caída del precio del café, etc.) explican en gran parte el escaso dinamismo de las cifras relativas a las exportaciones agropecuarias regionales. Otros factores fueron la actitud proteccionista de los países importadores y, posiblemente, algunas ineficiencias en el proceso de comercialización.

El estancamiento del valor de las exportaciones agropecuarias regionales frente al de las exportaciones regionales totales, que creció un $8 \%$ entre 1984 y 1989 , ha significado una reducción de la importancia relativa del sector agropecuario en el comercio exterior regional. Las exportaciones agropecuarias que en 1984 constituían, en valor, el $28.2 \%$ del total de las exportaciones regionales, bajaron en 1989 al $25.9 \%$. 
Cuadro 1

AMERICA LATINA Y EL MUNDO: LA EVOLUCION DE LAS EXPORTACIONES DE PRODUCTOS AGROPECUARIOS, 1978-1989

(Nümeros indices 1979.1981 $=100)$

\begin{tabular}{|c|c|c|c|c|c|c|c|c|c|c|c|c|}
\hline & 1978 & 1979 & 1980 & 1981 & 1982 & 1983 & 1984 & 1985 & 1986 & 1987 & 1988 & 1989 \\
\hline \multicolumn{13}{|c|}{ Volúmenes } \\
\hline América Latina & 95 & 98 & 92 & 111 & 104 & 121 & 116 & 127 & 109 & 106 & 114 & 113 \\
\hline Mundo & 89 & 92 & $10]$ & 106 & 105 & 105 & 109 & 108 & 107 & 114 & 117 & 120 \\
\hline \multicolumn{13}{|c|}{ Valores unitarios } \\
\hline América Latina & 89 & 95 & 113 & 92 & 87 & 79 & 90 & 79 & 92 & 85 & 91 & 90 \\
\hline Mundo & 86 & 98 & 108 & 98 & 90 & 88 & 90 & 85 & 93 & 95 & 104 & 107 \\
\hline \multicolumn{13}{|c|}{ Valores globales } \\
\hline América Latina & 84 & 93 & 104 & 102 & 91 & 97 & 105 & 101 & 102 & 91 & 104 & 102 \\
\hline Mundo & 77 & 91 & 105 & 105 & 95 & 93 & 98 & 92 & 99 & 108 & 122 & 128 \\
\hline
\end{tabular}

Fuente: FAO, Anuario de conercio 1989, Roma, 1990.

Como factor de comparación puede señalarse que en el mismo período las exportaciones forestales y pesqueras crecieron $52.1 \%$, llegando a representar en 1989 el $4.7 \%$ de las exportaciones regionales totales, contra el $3.7 \%$ en 1984 .

Cabe destacar que, de todas maneras, el relativo estancamiento que se produjo en la segunda mitad de los años ochenta fue posterior a la importante fase de expansión que caracterizó a la primera mitad de la década. En el período 1978-1984 las exportaciones agropecuarias latinoamericanas crecieron más rápidamente que el promedio mundial, tanto en términos de volúmenes como de valores globales (cuadro 1).

Además, hay que tener presente que aun en una situación de lento crecimiento de las exportaciones globales, como fue la de la región en la segunda mitad de los años ochenta, hubo productos y países que tuvieron un buen desempeño. En efecto, si se observa en detalle, el panorama de las exportaciones agropecuarias latinoamercanas y caribeñas aparece bastante articulado, con sectores y países que profundizaron procesos de transformación productiva bastante avanzados. Particularmente dinámicas fueron las exportaciones de productos no tradicionales. Asimismo, no todos los productos tradicionales de exportación pasaron por etapas de crisis o de estancamiento. Por el contrario, el desempeño de los países exportadores de la región fue bastante bueno respecto de algunos productos, en particular el algodón y el banano.

\section{Los productos no tradicionales}

Actualmente, una de las características más interesantes del comercio internacional de productos agropecuarios de América Latina y el Caribe reside en el desempeño prometedor de las exportaciones no tradicionales. ${ }^{4}$ En algunos países, las mayores ganancias provenientes del aumento de las exportaciones no tradicionales permitió equilibrar o superar el impacto de la caída de rubros exportadores tradicionales. Por ejemplo, en Brasil el aumento de ingresos debido a las exportaciones de productos a base de soya y de jugo de naranja (1 908 millones de dólares más en 1989 que en 1986), compens 6 holgadamente la reducción del valor de las exportaciones de café y de azúcar (581 millones de dólares menos en 1989 que en 1986). ${ }^{5}$

Sin embargo, a pesar de la evolución satisfactoria de las exportaciones no tradicionales de muchos países de la región, ${ }^{b}$ es difícil prever el grado de estabilidad y las reales perspectivas de

${ }^{4}$ La definición de producto no tradicional de exportación no es rigurosa y muchas veces varía de un pais a otro. En general, se define como no tradicional cualquier producto agropecuario cuya exportación era inexistente o muy limitada antes del periodo 1975-1980.

"Datos del Banco de Brasil, Cartera de Comercio Exterior. Véase también cil'Al. (1990).

${ }^{6}$ Aparte de Brasil, hay otros casos de desarrollo agroexportador basado en rubros no tradicionales que han sido muy estudiados por los especialistas del sector, y muy a menudo citados por los medios de información. Son los de Colombia 
expansión a largo plazo del comercio internacional de estos productos. En cualquier momento puede haber trastornos inesperados en los mercados de determinadas hortalizas, flores o frutas. A veces la alta rentabilidad de algunos productos -en particular los de clima templado y fuera de temporada- ha inducido a un número creciente de países a empezar o acrecentar el cultivo y la exportación de dichos productos, provocando después de un tiempo la saturación del mercado y la caída de los precios y de la rentabilidad. Algo así ha sucedido con los mercados de espárragos y frambuesas frescas, cuya crisis ha afectado a algunos países latinoamericanos en los últimos años.

El problema de algunos productos no tradicionales es su vulnerabilidad intrínseca, ${ }^{7}$ relacionada muchas veces con su carácter de producto de lujo, destinado a un porcentaje relativamente pequeño de consumidores de los países industrializados. Estos productos son extremadamente sensibles al ciclo económico de los páses importadores, sobre todo por sus precios más bien altos y también porque su consumo - a diferencia del de productos tradicionales como el plátano- no se ha transformado en un hábito regular en los países importadores. El consumidor considera allí que estos productos son atractivos pero no esenciales, y puede renunciar a ellos con mucha facilidad. Es importante, por lo tanto, que exista una buena comunicación entre los exportadores de los países en desarrollo y los importadores en los países de destino, particularmente en lo que atañe a las tendencias de la demanda. En general, los países exportadores de productos no tradi- cionales deben prestar mucha atención a la información sobre los mercados y sobre la oferta competitiva.

Las características comerciales de un producto no tradicional pueden cambiar con los avances en las técnicas de almacenamiento y de transporte. En el caso, por ejemplo, de la fruta fresca, sea ésta tropical o de fuera de temporada, la posibilidad de pasar del transporte aéreo al transporte marítimo, reduciendo en forma importante su precio, abre nuevos mercados en los países importadores y de alguna forma facilita el proceso de incorporación del producto en los hábitos regulares de consumo de esos países.

Para otros productos, en particular los de uso agroindustrial, sean o no exportados en forma semielaborada - como los granos y las tortas de soya-los mercados pueden presentar curvas de precios que tienden a descender en el mediano y largo plazo, por la existencia de un potencial de producción superior a las posibilidades de la demanda. Vale decir, para algunos productos no tradicionales, con el tiempo pueden empezar a funcionar los mecanismos que tienden a deprimir los mercados de los productos básicos tradicionales.

Por todo lo anterior, y considerando la experiencia de los últimos años, se puede afirmar que los países que quieren expandirse con éxito en rubros agroexportadores no tradicionales tienen que procurar que su oferta sea lo más diferenciada posible y esforzarse, además, por lograr una flexibilidad productiva y comercial que les permita ajustarse a mercados cuyos rasgos esenciales cambian con una velocidad considerable.

\section{Los mercados internacionales en los años noventa}

Según la proyección media "más probable" de las Naciones Unidas, en el año 2025 la población mundial sumará 8504 millones de personas, con

(flores cortadas, fruta tropical), Chile (fruta, hortalizas), Guatemala (hortalizas), México (hortalizas), Paraguay (semilla de soya) y Perú (fruta tropical, hortalizas). Esta lista muy incompleta muestra, sin embargo, la concentración de la mayoría de los países en rubros productivos similares.

7 Algunos estudios especificos que han tenido en debida consideración el carácter oligopsónico de muchos mercados un aumento neto de 3104 millones en relación al nivel supuestamente alcanzadoen 1991 (Fitar,

de productos no tradicionales han llegado a la conclusión de que los paises exportadores tienden a aceptar más que a fijar los precios. Este fenómeno se da también en el caso de países que controlan una cuota importante del mercado de un determinado producto no tradicional. Por ejemplo, en el mercado norteamericano pasa la uva de fuera de temporada, un pais exportador como (hile no loggra ejercer una intluencia determinante sobre los precios, pese a que controla alrededor del $25 \%$ del mercado. 
1991). Con este crecimiento, la demanda potencial de productos agrícolas a nivel mundial tendría que aumentar considerablemente en los próximos años, tanto en lo que se refiere a productos alimenticios como a materias primas de origen vegetal y animal.

Al mismo tiempo, es difícil prever en qué proporción dicha demanda potencial se transformará en demanda efectiva. De hecho, el $95 \%$ del aumento previsto de población corresponderá a los países en desarrollo, sobre todo en Asia meridional, en Africa, en América Latina y el Caribe y en el Medio Oriente. En cambio, se prevé que en la mayoría de los paises de Europa, América del Norte y Oceanía el crecimiento natural de la población será muy bajo (inferior al $1 \%$ ) o nulo. También en Asia oriental el crecimiento de la población se está estancando. Japón ya ha alcanzado tasas de fecundidad por debajo del nivel de reemplazo, con una media de menos de dos hijos por familia, y China posiblemente las alcanzará hacia finales de siglo; similar es la situación en la República de Corea y Tailandia.

Así, en las regiones con mayores perspectivas de crecimiento económico, la población, y por lo tanto la demanda potencial de productos agrícolas, crecerá a ritmos muy lentos. Por el contrario, en regiones como Africa o América Latina - más dependientes de la exportación de productos agropecuarios-el sector agrícola tendrá que aumentar su producto en cantidades suficientes para alimentar los nuevos contingentes de población, $y$, al mismo tiempo, tendrá que generar un superávit comercial suficiente para financiar las importaciones de productos industriales.

Puede ser útil esbozar rápidamente un cuadro que permita determinar la posición neta real de las grandes áreas del mundo en el mercado internacional de productos agrícolas. Con este propósito utilizaremos el concepto de saldo agricola (Boulard, 1990). A to largo de los últimos veinticinco años las areas deficitarias han sido cuatro: i) Europa occidental; ii) Japón; iii) Europa oriental y la Unión Soviética, y iv) los países del Golfo Pérsico. Japón ha mantenido su déficit relativamente constante, mientras que los paises del Golfo lo han visto crecer en el curso de los años ochenta. Los datos más interesantes son los del aumento del déficit de Europa oriental y la fuerte reducción de la posición deficitaria de Europa occidental. Esta última es hoy, al mismo tiempo, el más grande exportador e importador mundial de productos agropecuarios. Tanto las importaciones como las exportaciones de Europa occidental crecieron rápidamente a lo largo de los años ochenta, pero la tasa de crecimiento de sus exportaciones fue sensiblemente mayor. Por ejemplo, en el período 1984-1989 las importaciones aumentaron acumulativamente en alrededor de $55.6 \%$, mientras que las exportaciones subieron $70.3 \%$. En muchos rubros Europa occidental es un exportador neto. En la base de esta expansión de sus exportaciones están los grandes excedentes que se han ido generando en muchos países miembros de la Comunidad Europea a raiz de la Política Agrícola Común (PAC) de la Comunidad y de sus mecanismos de ayuda a la producción.

Entre las áreas con superávit, Estados Unidos tiene los saldos activos más altos; sin embargo, esos saldos se caracterizan por experimentar fuertes oscilaciones que hacen variar su valor entre el 5 y el 15 a $16 \%$ de las exportaciones agropecuarias mundiales. Estados Unidos obtiene su superávit principalmente de la exportación de cereales.

América Latina, la otra gran área excedentaria, es el principal proveedor de Estados Unidos para la mayoría de los productos agrícolas, aparte de los cereales (60\% en 1988). También los saldos de América Latina fluctúan marcadamente por la interacción de la dinámica de las exportaciones de productos tropicales, materias primas agrícolas, cereales y carne de vacuno, por un lado, y de las importaciones de productos alimenticios, por otro.

Otras áreas excedentarias, como Canadá, Australia, Nueva Zelandia y algunos países asiáticos, muestran saldos positivos más estables. Por el contrario, en Africa, que a fines de los años sesenta presentaba un importante saldo agrícola positivo -igual a casi el $10 \%$ del valor de las exportaciones agropecuarias mundiales-el superávit se redujo progresivamente bajo la presión de las crecientes importaciones de productos alimenticios y de la caída de los precios de sus principales productos de exportación.

Este es el cuadro de fondo cuyos rasgos esenciales difícilmente podrán ser modificados en el mediano plazo. Veamos ahora cuáles son las oportunidades que podrian surgir en los mercados como consecuencia de los grandes procesos 
de transformación socioeconómica que están ocurriendo en algunas regiones (Europa oriental, el Lejano Oriente) y de las tendencias mundiales a la liberalización del comercio.

En efecto, es posible que se generen importantes cambios en las estructuras del sistema agroalimentario mundial, que traerían consigo aumentos en la demanda de productos agrícolas originarios de los países en desarrollo. Estos cambios podrían resultar de tres procesos paralelos actualmente en curso en el mundo, cuyo desenlace no es aún completamente previsible. Estos procesos son: i) la transformación social, económica y política de los países de Europa oriental y de las repúblicas de la ex Unión Soviética; ii) el proceso de industrialización y la rápida expansión del PIB en muchos países del Lejano Oriente, $y$ iii) las negociaciones en el marco de la Ronda Uruguay sobre la liberalización del comercio internacional de productos agrícolas.

A continuación analizaremos brevemente los efectos que estos procesos podrían tener en el intercambio mundial de productos agropecuarios, y lo que esto podría significar para los países en desarrollo.

\section{Los efectos de los cambios al este del Elba}

Los intensos procesos de transformación social, política y económica que están teniendo lugar en los países de Europa oriental y en las ex repúblicas soviéticas afectarán en dos distintas formas la estructura del sistema agroalimentario mundial: de un lado, crecerá la demanda global de estos países; del otro, aumentará su oferta de productos agrícolas. Los dos fenómenos han de ser de interés particular para los países en desarrollo que, en el mediano plazo, tendrán que organizarse para aprovechar las oportunidades y limitar los riesgos que traiga consigo la entrada de nuevos e importantes protagonistas en el mercado agrícola mundial.

Es indudable que una aceleracion del ritmo de crecimiento del pIB en los países de Europa oriental y en las repúblicas de la disuelta Unión Soviética elevaría la demanda de algunos productos originarios de los países en desarrollo, particularmente de América Latina y el Caribe. Un mejor nivel de vida en el que fue el mundo comunista se traduciría en mayores importaciones de bebidas tropicales (té, café y cacao), fruta tropical, algodón, azúcar y otros rubros. Pero aunque la mayoría de los analistas afirman que en el mediano o largo plazo estos países deberian experimentar un importante proceso de crecimiento económico, no es posible prever con certeza su dimensión ni su ritmo, ni el plazo en el cual el PIB y la demanda empezarian a crecer en forma significativa. Por lo tanto, es todavía demasiado temprano para cuantificar esas variables.

Más probable en el mediano plazo podría ser un aumento de las exportaciones de productos agropecuarios desde algunos de estos paises - en particular los más cercanos a la cE.E- hacia los países de la ocDE Los cambios radicales ya introducidos en países como Hungría y Polonia están causando aumentos importantes de su productividad agrícola. En 1988 ambos países llegaron a un acuerdo con la cer, que les permite exportar sus productos agrícolas a la Comunidad libres de impuestos. A la vez, bajo el poderoso estímulo de la liberalización de los mercados internos, los agricultores húngaros y polacos han incrementado marcadamente sus producciones, mientras que el consumo interno ha seguido estancado o hasta en baja como consecuencia de la eliminación de los controles sobre los precios. Esta situación se ha traducido en la rápida generación de importantes excedentes exportables.

Según algunas estimaciones (Fottorino, 1991), los excedentes exportables de mantequilla de Polonia, un país tradicionalmente importador de este producto, serían de 70000 toneladas. Checoslovaquia ya tiene la capacidad de exportar cerca de 40000 toneladas de leche en polvo. Y varios países de Europa oriental también tienen capacidad exportadora de carne de vacuno y de animales. (Se estima que en 1990 estos paises vendieron alrededor de 80000 cabezas de bovinos a bajo precio.)

Si el potencial exportador de productos agropecuarios de los países de Europa oriental no es despreciable, el de las repúblicas de la ex Unión Soviética podría ser mucho más importante en el largo plazo. Aunque en su estado actual la agricultura soviética es deficitaria en su conjunto, esto no significa que lo será indefinidamente. Varios analistas consideran que de aquí al año 2000 por lo menos algunas de las repúblicas de la disuelta Unión Soviética, como Ucrania, podrían recuperar la calidad de exportadoras de 
Cuadro 2

UNION SOVIETICA: PRODUCCION TOTAL DE CEREALES, 1986-1990

(Miles de toneladas métricas)

\begin{tabular}{|c|c|c|c|c|c|c|c|}
\hline & 1986 & 1987 & 1988 & 1989 & 1990 & $\begin{array}{r}\text { Promedio } \\
1986-1990\end{array}$ & $\begin{array}{l}\% \text { del } \\
\text { total }\end{array}$ \\
\hline Rusia (RSFSR') & 117968 & 109084 & 102807 & 112360 & 127000 & 113844 & 53.5 \\
\hline Ucrania & 43063 & 50184 & 47388 & 54900 & 53200 & 49747 & 23.4 \\
\hline Moldavia & 2044 & 2011 & 3052 & 3538 & 2600 & 2649 & 1.2 \\
\hline Bielorrusia & 7041 & 9281 & 6922 & 7900 & 8200 & 7869 & 3.7 \\
\hline Kazastán & 28306 & 27444 & 22560 & 20200 & 31200 & 25942 & 12.2 \\
\hline Repúblicas transcaucásicas & 2035 & 2057 & 2504 & 1607 & 2400 & 2121 & 1.0 \\
\hline Asia Central & 3447 & 4443 & 4775 & 4071 & 4400 & 4227 & 2.0 \\
\hline Repúblicas bálicas & 6164 & 6897 & 5050 & 6324 & 6800 & 6247 & 2.9 \\
\hline Total & 210068 & 211401 & 195058 & 210900 & 235800 & 212645 & 100.0 \\
\hline
\end{tabular}

Fuente: Departamento de Agricultura de Estados Lnidos, Servicio Exterior de Agricultura

" República soviética federativa socialista rusa

cereales que tenían antes de 1917. Otros piensan que esto dificilmente podría pasar antes de los años 2005 a 2010 . De todas maneras, considerando el tamaño actual del sector cerealero de las ex repúblicas soviéticas, ${ }^{8}$ la hipótesis de un desarrollo agroexportador en el mediano plazo tiene que ser considerada con extrema seriedad (cuadro 2).

\section{El potencial de los mercados asiaticos}

En el mediano plazo, es posible que también surjan oportunidades para los países agroexportadores en los mercados de los países asiáticos. En los últimos años estos países han experimentado y continúan experimentando tasas de crecimiento que se hallan entre las más altas del mundo. ${ }^{9}$

${ }^{8}$ En 1989 la producción soviética de cereales representó el $\$ 0.9 \%$ del total mundial. En el mismo año la producción de Estados Unidos represent 6 el $15.2 \%$ del total y la de Argentina el $0.9 \%$ (1.2\% en 1988 ).

"Aunque en 1989 se desaceleró el crecimiento económico en Asia y el Pacifico, éste siguió siendo uno de los más rápidos del mundo. La tasa real de aumento del Pris agregado de la región bajó al $5.3 \%$ en 1989 , desde la cifra sin precedentes de $9.4 \%$ registrada en 1988 . China e India, las dos mayores cconomías asiáticas después de Japón, tegistraron una baja bastante aguda del crecimiento del Prß. En China, éste se redujo del $11.2 \%$ en 1988 al $3.9 \%$ en 1989 , en tanto que en la India descendió de la cifra sin precedentes de $9.5 \%$ en 1988 a $4.5 \%$ en 1989 . En este último año, el pIB agricola creció $4.5 \%$ en China y $2.0 \%$ en India. En la región, solamente Nepal, Papua, Nueva Guinea y Samoa experimentaron en
En cuanto al crecimiento del comercio internacional de productos agrícolas de los países asiáticos en los últimos años, entre 1984 y 1989 las importaciones agrícolas de los nueve paises considerados crecieron $58.4 \%$. Las tasas más altas de incremento de las importaciones agrícolas corresponden a China, Corea del Sur, Tailandia y Hong-Kong, cuyas importaciones se elevaron, en términos porcentuales, más que las de Japón. Al mismo tiempo, también las exportaciones agrícolas globales de estos países aumentaron a un ritmo alto -alrededor de $45 \%$ - entre 1984 y 1989. En este mismo período, el crecimiento de

1989 tasas de crecimiento del p1B inferiores al $2 \%$. No se registró ninguna tasa negativa. En cambio, la República de Corea, Singapur, Tailandia, Indonesia, Malasia, Filipinas, Pakistán, Fiji, las Maldivas y Taiwán (provincia de China), tuvieron tasas de crecimiento del PIB superiores al $5 \%$. Tailandia, con una tasa de aumento del $10.8 \%$, fue la economía que registró el crecimiento más rápido del mundo en 1989. De manera análoga, varios países obtuvieron excelentes resultados en el sector agricola durante 1989. En Nepal, Pakistán, Myanmar (antes Birmania), Fiji y Vietnam, el PIB agrícola se incrementó en un $6 \%$ o más en esc año. Indonesia, Laos, Malasia, Tailandia y Filipinas registraron tasas de crecimiento agrícola que iban del 3.5 al 4\%. En 1989 la región de Asia generó casi $90 \%$ de la producción arrocera mundial y $42 \%$ de la producción mundial de cereales. China, India, Bangladesh y Tailandia obtuvieron cosechas de arroz sin precedentes gracias a una combinación de buen tiempo, mayor uso de variedades de alto rendimiento y aumento de la superficie plantada con este cereal. 
Cuadro 3

ALGUNOS PAISES DEL LEJANO ORIENTE: IMPORTACIONES Y EXPORTACIONES DE PRODUCTOS AGROPECUARIOS, 1984-1989 (Millones de dólares)

\begin{tabular}{|c|c|c|c|c|c|c|c|c|c|c|c|c|c|c|c|c|}
\hline & \multicolumn{10}{|c|}{ Importaciones } & \multicolumn{6}{|c|}{ Exportaciones } \\
\hline & & 1984 & & 1985 & & 1986 & & 1987 & 1988 & 1989 & 1984 & 1985 & 1986 & 1987 & 1988 & 1989 \\
\hline Japón & 18 & 446.4 & 16 & 865.9 & 18 & 129.8 & 20 & 934.3 & 26805.4 & $\begin{array}{lll}29 & 059.5\end{array}$ & 853.7 & 755.3 & 834.6 & 947.5 & 1016.3 & 1073.6 \\
\hline China $^{2}$ & 5 & 736.7 & & 785.1 & 5 & 386.4 & 7 & 439.9 & 9740.2 & $11 \quad 074.8$ & 5589.6 & 6248.0 & 7886.9 & 9056.7 & 10058.8 & $10 \quad 168.5$ \\
\hline $\begin{array}{l}\text { República } \\
\text { de Corea }\end{array}$ & & 481.4 & & 074.7 & & 267.1 & 4 & 055.6 & 5282.5 & 6308.5 & 562.1 & 502.4 & 590.0 & 747.1 & 1006.2 & 1106.4 \\
\hline Hong-Kong & & 569.6 & & 542.0 & & 707.3 & 4 & 758.9 & 5738.1 & 6293.3 & 1279.9 & 1467.8 & 1644.9 & 2173.4 & 3020.3 & 3272.3 \\
\hline Singapur & 2 & 801.1 & & 436.2 & & 292.3 & 2 & 451.1 & 3058.0 & 3196.5 & 2205.5 & 1832.1 & 1742.6 & 1828.4 & 2306.6 & 2434.7 \\
\hline Malasia & & 634.0 & & 465.9 & & 300.2 & 1 & 488.1 & 1852.9 & 2067.2 & 4641.9 & 3717.9 & 3305.0 & 4082.7 & 5181.9 & 4620.5 \\
\hline Tailandia & & 651.1 & & 547.9 & & 571.1 & & 771.9 & 1056.6 & 1248.8 & 3821.3 & 3202.7 & 3596.0 & 3949.0 & 5045.5 & $\begin{array}{ll}6 & 010.2\end{array}$ \\
\hline Indonesia & 1 & 117.1 & & 903.5 & & 934.7 & 1 & 124.0 & 1319.3 & 1625.2 & 2462.0 & 2475.2 & 2528.3 & 2769.9 & $3 \$ 23.0$ & 3184.4 \\
\hline India & 1 & 941.6 & & 650.5 & I & 311.3 & 1 & 582.7 & 2319.8 & 1426.7 & 2259.2 & 2264.6 & 2376.1 & 2373.4 & 2207.4 & 2469.0 \\
\hline Total & 39 & 329.0 & 35 & 271.7 & 36 & 900.2 & 44 & 606.5 & 57172.7 & $62 \quad 299.7$ & 23678.2 & 22466.0 & 24504.4 & 27928.1 & 33166.0 & 34339.6 \\
\hline
\end{tabular}

Fuente: FAO, Aruario de comercio, 1989, Roma, 1990.

Incluye Tajwán. 
las exportaciones agricolas fue más marcado en China $(81 \%)$ y Tailandia $(57.2 \%)$. Así, China casi ha dejado de ser un país deficitario, y Tailandia, Malasia, Indonesia e India son exportadores netos (cuadro 3).

Interesante es notar que, junto con el desarrollo agroexportador, en varios países se observa un crecimiento importante de la agroindustria. En el curso de los años ochenta otras dos naciones, Tailandia y Malasia, se unieron al grupo de los países asiáticos de industrialización reciente. ${ }^{16}$ Pero, a diferencia de lo que habia pasado hasta ahora con otros países de la región, incluidos en esta categoría, Tailandia y Malasia están desarrollando, dentro de un sector industrial en rápida expansión, ${ }^{11}$ un importante subsector agroindustrial estrechamente ligado a la agricultura de exportación (FAO, 1990c, p. 55). Por ejemplo, en Tailandia, la tasa de crecimiento anual media de las exportaciones de aves congeladas en 1984-1989 fue de $26 \%$ y la de piña tropical en conserva alcanzó un $14 \%$. En el mismo período, las exportaciones de productos elaborados de Malasia crecieron a una tasa anual media de $10 \%{ }^{12}$

El éxito de Tailandia y Malasia en aumentar la producción y el comercio de productos agro- pecuarios tradicionales y no tradicionales, junto con su capacidad de crear un complejo agroindustrial dinámico y agresivo con el fin de exportar productos de alta calidad, explica por qué se les considera países recientemente agroindustrializados (FAO, 1990c, p. 55).

El dinamismo de la región asiática, uno de los fenómenos socioeconómicos más relevantes de este fin de siglo, abre oportunidades pero también significa amenazas para los países agroexportadores latinoamericanos. De un lado, su crecimiento económico y la creciente capacidad de consumo de sus habitantes van creando nuevos mercados para la producción de los países latinoamericanos y caribeños. De otro, el gran dinamismo de los agroexportadores asiáticos puede reducir con el tiempo las cuotas de mercado actualmente contratadas por las empresas latinoamericanas, no sólo en la misma región asiática sino que también en Europa o América del Norte.

En efecto, en el principal mercado asiático, Japón, la presencia de las producciones latinoamericanas no es muy grande (5.9\% en 1988 ), a pesar de las grandes posibilidades de complementación entre la economía de este pais y la de los países agroexportadores latinoamericanos y caribeños.

\section{III}

\section{La Ronda Uruguay}

\section{La dimensión histórica del proteccionismo agricola}

La dirección que tomarán los procesos de cambio en los paises de Europa oriental, así como los

\footnotetext{
${ }^{11}$ Fin los años anteriores esta definición habfa sido aplicada en Asia a Hong-Kong, la Repuiblica de Corea, 'laiwán (provincia de China) y Singalpur.

"En los años ochenta la tasa de creciniento antal del sector indust rial fue, en promedio, cle $30 \%$ en Tailandia y de 20\% en Malasia.

${ }^{12}$ Este crecimiento del sector agroind ust rial ha sido parte de un crecimiento general de las industrias transformadoras de recursos naturales renovables. Por ejempto, en los años ochentit las exportaciones tailanclesas cle pescado y camarom en conserva aumentaron a tha lasa media anual de $29 \%$ y las exporlaciones de productos de madera a una de $21 \%$. Malasia vio crecer sus exporlaciones de manulacturas basadas en el caucho y en productos de madera a rasas antales medias de 33 y $10 \%$, respectivamente.
}

procesos de desarrollo acelerado que registra el Lejano Oriente, influirán de manera determinante en la evolución del comercio mundial de productos agricolas en las próximas décadas. Sin embargo, a corto plazo, las novedades más importantes podrían surgir de las negociaciones comerciales multilaterales en el ámbito de la octava ronda del ciATs, la Ronda Uruguay. Su desenlace revestirá la máxima importancia para el comercio mundial en general y para los productos agropecuarios en particular. En efecto, la novedad más importante de la Ronda Uruguay respecto de otros ciclos de negociaciones anteriores del (iA Tha sido el gran espacio reservado a los temas agrícolas en la agenda. ${ }^{13} \mathrm{Al}$ avanzar los debates,

\footnotetext{
1:t En el ámbito del (AAC' los temas agricolas habjan sido discutidos ya en la Ronda Dillon (1960-1962), y más aún en
} 
parece evidente que el éxito de la Ronda en su conjunto dependerá de la posibilidad de llegar a un acuerdo sobre la liberalización del comercio de productos agropecuarios.

Otra caracteristica importante de la Ronda Uruguay es la amplitud de las negociaciones, las cuales abarcan no sólo las medidas de protección, como aranceles y contingentes de importación, sino también las políticas de subvención a las exportaciones agricolas y el tema fundamental de los subsidios y otras medidas de sustentación de la producción agrícola interna.

Un eventual desenlace exitoso de esta Ronda podría conducir a una fundamental inversión de tendencia, después de más de un siglo de proteccionismo agricola. ${ }^{14}$ En efecto, a partir de la depresión de los últimos veinte años del siglo XIX los países europeos empezaron, uno después de otro, a proteger con aranceles sus producciones agrícolas amenazadas por la competencia de Rusia y de los nuevos productores de entonces, es decir, Estados Unidos, Canadá, Australia, Nueva Zelandia y Argentina.

Las razones principales que se aducían para justificar la protección eran: i) la exigencia de mantener un determinado nivel de autosuficien(ia alimentaria; ii) consideraciones relacionadas con la "especificidad del sector"; ${ }^{5: 5}$ y iii) la necesidad de proteger el nivel de vida de las poblaciones residentes en las áreas rurales. ${ }^{\text {ti }}$

la konda kenneds, en la cual tomó cuerpo, do forma ya bastante definida, la contraposicion entre la Commidad Economic a Europeat Estados L'nidos. En la Ronda Tokio (197679). la agricultura constituro uno de los principales puntos de tension y las discusiones se conplicaron también por falta de acuerdo entre Estados Lnictos \& la ctit. en materia de procedimienuo. Lat experiencia de la Ronda Tokio llevó a la const jución en I982 de un Comité para el Comercio Agrícola constituido por representantes de 57 naciones con una significativa presencia de paises en desarrollo. los trabajos del Comité permitieson identiticar con precisión los temas y los procedimientos de negociación de la Ronda Lruguay. Para talı análisis detallado del papel de la agricultura en el ámbito del (a:1"I, vease Basile (1991), Hattawar (1987) y Mine. Ingersent y Ravner (1989).

${ }^{H}$ Jara matores informaciones sobre la cwolución hisiórica del proteccionisno agricola yéase: K. Anderson y' Y. Harami (1986). Basile (1990) y Jones (1989).

": El concepto de "especificidad" del sector agricola hace referencia al hecho de que la actividad agricola enfrenta un indice de riesgo superior al de otros sectores productivos. Esto porque al riesgo propio de cualquier activid ad económica hay que añadir los riesgos dimáticos y fitosanitarios.

ition el tiempo los sostenedores del proteccionismo
Con la crisis de los años treinta, la lógica proteccionista se extendió a Estados Unidos, país que a partir de esa década, tuvo una actitud aperturista en materia de comercio de productos manufactureros, y proteccionista en materia de comercio agrícola.

Después de la segunda guerra mundial, Estados Unidos pasó de la defensa de su agricultura a la promoción activa de sus exportaciones agrícolas. Desde su punto de vista se trataba de tutelar una ventaja comparativa natural. Entre los primeros años del decenio de 1950 y el comienzo del de 1970, las exportaciones agrícolas de Estados Unidos se cuadruplicaron y empezaron a desempeñar un papel más importante en la compensación de los déficit comerciales, cada vez mayores a partir de esa época.

Mientras Estados Unidos se planteó como pats exportador y la cie. como área importadorá, el conflicto entre el énfasis agroexportador norteamericano y el proteccionismo agrícola europeo se mantuvo latente. Sin embargo, cuando la Comunidad empezó a desarrollar un importante potencial exportador en directa competencia con Estados Unidos, el conflicto comercial se manifestó en formas cada vez más abiertas.

Junto con intensificarse el conflicto, se refinaron y diversificaron los instrumentos proteccionistas. ${ }^{17} \mathrm{~A}$ los aranceles se fueron sumando las restricciones cuantitativas, las imposiciones no arancelarias, las barreras técnicas y aduaneras y las distintas formas de intervención directa del Estado en los mercados agrícolas (con subsidios a la producción y la exportación, adquisiciones de productos por agencias gubernamentales en defensa de los precios, e intervención político-diplomática para el logro de acuerdos de autolimitación voluntaria con otros países).

A la evolución de esos instrumentos correspondió, a lo largo de los últimos cien años de proteccionismo, una evolución de los objetivos. Se fue pasando progresivamente de políticas de cierre de los mercados o de reforzamiento de ventajas comparativas naturales a políticas de

han subrayado también la "especial relevancia social" del sector agrícola, en térninos tanto laborales como de equilibrios, politicos y territoriales.

${ }^{17}$ Se ha hablado de una escalada o progresión (escralation) de los instrumentos proteccionistas. Véase Basile (1941). 
creación de condiciones artificiales de competitividad para los productores agrícolas nacionales.

Es importante destacar que los problemas del comercio internacional de productos agrícolas tienen relevancia política, entendiendo con esto no sólo las implicaciones del tema en la política interna de los diversos países (peso electoral de los agricultores, precios de los alimentos, políticas regionales, etc.), sino también la creciente dimensión político-internacional del intercambio agrícola. De hecho, casi podría parecer una paradoja que en la última década del siglo $\mathrm{xx}$ el aspecto más controvertido de las relaciones comerciales entre las dos mayores áreas económicas del planeta, Estados Unidos y la CEE, sea la agricultura. Esta dimensión político-internacional de los temas agricolas está destinada a perdurar por varios años, cualquiera sea el desenlace de la Ronda Uruguay, debido a la relevancia cada vez mayor que los equilibrios agroalimentarios tendrán para la estabilidad de varias regiones de Africa, de Asia meridional y, en perspectiva, de América Latina.

\section{Las posiciones de los distintos actores}

Las reglas del (AATT en materia de agricultura son relativamente pocas, bastante genéricas y además formuladas en términos ligeramente ambiguos. De alguna forma están fuertemente condicionadas por las prioridades que las partes contrayentes tenían en el momento en el cual el acuerdo fue ratificado. En efecto, en armonía con el objetivo de permitir la afirmación de un sistema de comercio mundial lo más libre posible, se evitó introducir en el texto alguna referencia o declaración de principio relativa a la "especificidad" del sector agrícola. Sin embargo, para permitir la reconstrucción de las agriculturas europeas se incorporaron algunas normas que, de hecho, iban a consentir distintos grados de protección de las producciones agrícolas nacionales. ${ }^{18}$

\footnotetext{
${ }^{1 H}$ Se trata, en primer lugar, de los articulos $\mathrm{x} I, \mathrm{xIl} y \mathrm{xIII}$, que permiten la adopcion de restricciones cuantitativas de las importaciones y de las exportaciones por distintas causas (crisis alimentarias, necesidad de control de la producción interna, problemas de equilibrio de la balanza de pagos). Estos artículos son muy importantes porque, en principio. en el (iNiT no se admite la adopción de estos instrumentos, por considerarlos una forma de protección "no transparente", en contraposición al arancel, ánica forma de protección
}

Lo que la Ronda Uruguay se ha propuesto modificar profundamente es, por lo tanto, un complejo de normas y de comportamientos establecidos que han regido el comercio agrícola internacional en los últimos cuarenta años. Además, ha habido la voluntad explícita de medir los obstáculos efectivos al comercio de productos agrícolas, y de establecer una clara conexión conceptual entre las políticas agricolas nacionales y la distorsión de los mercados.

Los principales protagonistas de los debates en esta Ronda han sido Estados Unidos; la (:EE; el Grupo de Cairns; ${ }^{19}$ Japón, Corea, los países escandinavos y Suiza, que comparten una fuerte sensibilidad hacia los temas de seguridad alimentaria interna, y los países en desarrollo importadores de alimentos. ${ }^{20}$

Esos debates han puesto de relieve sobre todo las discrepancias entre los dos negociadores principales, la cer y Estados Unidos, acerca de tres puntos:

i) La arancelización de los obstáculos a las importaciones, vale decir, la conversión de los obstaculos no arancelarios en derechos aduaneros que, en un primer momento, proporcionarian una protección equivalente, y con el tiempo podrian ser reducidos gradualmente a cero. Respecto a este punto, hasta ahora no se ha logrado un acuerdo por varias cuestiones técnicas vinculadas a los criterios de determinación de los

\footnotetext{
"transparente". En seguida, el artículo xvi, de compleja y no muy definida formulación, permite de hecho la adopción de subsidios. Es importante destacar que lo genérico de los criterios y del marco de referencia elegidos en este artículo para disciplinar la adopción de subsidios está en la base de la gran mayoria de liss controversias en el ámbito del (;ATl entre Estados Unidos y la c.Fe en 1976-1986. Finalmente, el artículo XXV.5 permite una exencion temporal de las obligaciones del GATI por "circunstancias excepcionales". Esta norma ha sido utilizada repetidas veces por Estados Unidos a partir de 1951 (productos lecheros).

${ }_{14}$ El Grupo de Cairns, de la homónima ciudad australiana, está integrado por 13 países que son grandes exporta. dores de productos agricolas: cinco países latinoamericanos (Argentina, Brasil, Colombia, Chile y Uruguay), cuattro paises asiáticos (Filipinas, Indonesia, Malasia y Tajlandia), tres paises occánicos (Australia, Nueva Zelandia y Fiji), y un país de Europa oriental (Hungria). Como puede verse, se trata de una agrupación de países bastante distintos en su estructura económica general, y que tienen como característica común la de ser exportadores eficientes de productos agrícolas de clima templado.

${ }^{20}$ Entre estos países un papel activo ha sido jugado principalmente por Egipto, Jamaica, Marruecos, México, Nigeria y Perú.
} 
Cuadro 4

ORGANIZACION DE COOPERACION Y DESARROLLO ECONOMICOS (OCOF)

TRANSFERENCIAS TOTALES A LA AGRICULTURA

(Miles de millones de dólores)

\begin{tabular}{|c|c|c|c|c|c|c|c|c|c|c|c|c|c|c|c|c|}
\hline & \multicolumn{4}{|c|}{$\begin{array}{c}\text { Transferencias fiscales } \\
\text { (1) }\end{array}$} & \multicolumn{4}{|c|}{$\begin{array}{c}\text { Transferencias pagadas por los } \\
\text { consumidores } \\
\text { (2) }\end{array}$} & \multicolumn{4}{|c|}{$\begin{array}{c}\text { Entradas fiscales } \\
\text { (3) }\end{array}$} & \multicolumn{4}{|c|}{$\begin{array}{c}\text { Tranferencias tobles } \\
\text { (1) }+(2)-(3)\end{array}$} \\
\hline & 1987 & 1988 & 1989 & 1990 & 1987 & 1988 & 1989 & 1990 & 1987 & 1988 & 1989 & 1990 & 1987 & 1988 & 1989 & 1990 \\
\hline Auscralia & 0.3 & 0.2 & 0.3 & 0.3 & 0.4 & 0.4 & 0.4 & 0.4 & - & - & - & - & 0.7 & 0.6 & 0.7 & 0.7 \\
\hline Austria & 1.0 & 1.0 & 0.8 & $1 . \mathrm{I}$ & 2.8 & 2.6 & 2.0 & 2.7 & - & - & - & - & 3.8 & 3.5 & 2.8 & 3. \\
\hline Canadá & 5.6 & 5.7 & 4.3 & 4.7 & 9.6 & 3.6 & 3.5 & 3.6 & 0.1 & 0.1 & 0.1 & 0.1 & 9.1 & 9.5 & 7.8 & 8.3 \\
\hline CE (12 paises) & 38.2 & 45.6 & 41.3 & 49.3 & 82.7 & 75.0 & 61.9 & 85.1 & 0.9 & 1.0 & 0.8 & 1.0 & 120.0 & 119.6 & 102.4 & 189.4 \\
\hline Finlandia & 1.6 & 1.8 & 1.7 & 2.2 & 3.1 & 3.3 & 3.2 & 3.8 & 0.3 & 0.1 & - & 0.1 & 4.4 & 5.0 & 4.9 & 5.9 \\
\hline Japón & 17.9 & 19.6 & 18.0 & 14.9 & 600 & 65.6 & 59.0 & 54.7 & 11.5 & 15.0 & 11.7 & 10.6 & 66.4 & 70.1 & 65.3 & 59.0 \\
\hline \multicolumn{17}{|l|}{ Nueva } \\
\hline Zelandia & 0.1 & 0.1 & - & - & 0.1 & 0.1 & 0.1 & 0.1 & - & - & - & - & 0.1 & 0.2 & 0.1 & 0.1 \\
\hline Noruega & 1.8 & 1.9 & 1.8 & 2.1 & 1.8 & 1.7 & 1.6 & 2.2 & 0.2 & 0.1 & 0.1 & 0.1 & 3.9 & $\$ .5$ & 5.3 & 4.2 \\
\hline Suecia & 0.6 & 0.6 & 0.5 & 0.5 & 2.7 & 2.6 & 2.7 & 3.0 & 0.2 & 0.2 & 0.1 & 0.1 & 3.1 & 9.0 & 3.1 & 3.4 \\
\hline Suiza & 1.7 & 1.8 & 1.8 & 2.1 & 4.5 & 4.7 & 3.9 & 4.9 & 0.8 & 0.8 & 0.6 & 0.7 & 5.4 & 5.7 & 5.0 & 6.2 \\
\hline Estados Unidos & 51.6 & 44.2 & 47.8 & 47.1 & 81.4 & 26.0 & 24.2 & 27.9 & 1.4 & 1.0 & 0.7 & 0.9 & 81.5 & 69.1 & 71.3 & 74.1 \\
\hline Total & 120.3 & 122.3 & 118.4 & 124.3 & 192.9 & 185.6 & 1626 & 188.3 & 15.3 & 18.4 & 14.2 & 13.6 & 297.8 & 289.6 & 266.7 & 299.0 \\
\hline
\end{tabular}

Fuente: Estrimación de la ocos.

'Las transferencias fiscales incluyen los impuestos estatales, federales y comunitarios.

${ }^{b}$ Las transfer encias pagadas por los consum idores representan los reem bolsos adicionales que los consumidores nacionales de los diversos países de la ocde tienen que enfrentar corno consecuenciz de la política de sustencación de los paises y de las medidas proteccionistas.

'Las entradas fiscales que se generan como consecuencia de las politicas de precio, se dan únicamente por productos en los cuales los paises no son autosuficientes. 
precios y de los años de referencia, y por la oposición de la Comunidad Europea a una "arancelización" que no contemple "coeficientes de corrección" aptos para proteger los ingresos de los agricultores frente a variaciones abruptas de los precios internacionales o a fluctuaciones de las tasas de cambio.

ii) La reducción de la ayuda interna y los criterios para medirla. La Comunidad Europea ofrecía una reducción del $30 \%$ de la ayuda global que se viene aplicando a los productos para los cuales se conoce la existencia de graves desequilibrios estructurales: arroz, cereales, azúcar, carne, alimentos proteicos, aceite de oliva y semillas oleaginosas. ${ }^{21}$ Esta propuesta ha sido considerada insatisfactoria por otros negociadores y por Estados Unidos en particular. Aún más paralizante ha sido la discrepancia entre Estados Unidos y la Comunidad Europea sobre los criterios para medir la ayuda interna efectiva. Los negociadores norteamericanos proponían la utilización de indicadores equivalentes del subsidio al productor (producer subsidy equivalent), mientras que la Comunidad Europea apoyaba la posibilidad de utilizar una unidad de medida de la ayuda interna (support measurement unit), porque individualiza esencialmente la ayuda que afecta a los mercados internacionales.

iii) Las subvenciones a la exportación. Estados Unidos propugna la eliminación total de esas subvenciones en un período de cinco años, mientras que la Comunidad Europea propone un sistema de reducción combinado con "coeficientes de corrección".

Tanto el tema de la ayuda interna como el de las subvenciones a las exportaciones son parte de una misma cuestión fundamental para los intereses de largo plazo de los países en desarrollo: la de las transferencias netas de recursos que los países industrializados regularmente hacen a sus agricultores para crear una competitividad artificial, eludiendo las diferencias de costo con los productores de los países en desarrollo. Para aquilatar la dimensión real de estas transferencias, cabe recordar, por ejemplo, que en 1988 las transferencias globales de los países de la OCDE a sus agriculturas representaron acumulativamente 266.7 billones de dólares, es decir, un valor

\footnotetext{
${ }^{21}$ Algunos de estos productos revisten una gran importancia para la región latinoamericana y caribeña.
}

comparable al de las exportaciones agropecuarias mundiales en el mismo año (287.2 billones de dólares). En 1989 esas transferencias crecieron aún más, llegando a representar 299 billones de dólares, en tanto que las exportaciones mundiales de productos agropecuarios fueron de 299.9 billones de dólares (cuadro 4 ).

Se puede observar en el cuadro 4 que, con la notable excepción de Australia y Nueva Zelan. dia, grandes exportadores de productos agropecuarios, todos los paises de la ocDe subsidian considerablemente su agricultura.

Es evidente que una reducción de los subsidios y, en general, un desenlace exitoso de la Ronda Uruguay, aumentaría considerablemente la competitividad relativa de los países en desarrollo exportadores de productos agropecuarios. Sin embargo, en el momento actual, los grandes procesos de apertura que están teniendo lugar en muchas regiones del mundo en desarrollo, y en América Latina y el Caribe en particular, están creando una situación desequilibrada entre un Sur aperturista y un Norte proteccionista.

Tras la reanudación de las negociaciones en la Ronda Uruguay, las perspectivas de llegar a un acuerdo en la agricultura podrían mejorar como resultado del debate sobre la reforma de la Política Agrícola Común que tiene lugar al interior de la $\mathrm{CE}$. El presupuesto agrícola, que absorbe las dos terceras partes del presupuesto total de la Comunidad, registró en 1991 un aumento del $20 \%$ en relación con el de 1990 , y cálculos iniciales sobre el presupuesto de 1992 arrojan un aumento posible de $12.6 \%$ respecto de 1991. Ante estos espectaculares incrementos, junto a los crecientes desequilibrios que existen en los mercados de cereales, carne bovina y ovina, leche y vino, la Comisión de la $C E$ ha preparado nuevas directrices para una reforma fundamental de la Política Agrícola Común. Si esta reforma es aprobada finalmente por los países miembros, podría abrirse la vía para un acuerdo en el marco de dicha Ronda (CEPAL, 1991).

Por lo demás, es importante tener presente que dentro de la misma Comunidad las posiciones de los distintos paises no son coincidentes. La preocupación principal de Alemania es la defensa de los niveles de ingreso de sus productores agricolas; otros paises, como Francia, quieren además defender la capacidad exportadora de su agricultura. Estas diferencias internas reducen 
marcadamente el margen de maniobra de los negociadores comunitarios.

Para los negociadores norteamericanos, por su parte, la defensa de su superávit agrícola es el objetivo principal. Estados Unidos, en particular, presenta regularmente un saldo exterior agrícola positivo. Pero en los últimos dos años dicho saldo positivo ha empezado a verse amenazado por la reducción de los volúmenes exportados y de los precios obtenidos. En otras palabras, las agroexportaciones estadounidenses han sufrido los efectos de los mismos fenómenos que afectan a las de algunos países en desarrollo. A la luz de esta coyuntura, y considerando la importancia que el superávit agrícola tiene para una balanza comercial deficitaria en su conjunto, como la de Estados Unidos, es fácil entender los esfuerzos que está haciendo este país para tener un mayor acceso a los mercados de Europa y Japón. Estos esfuerzos estadounidenses son prueba evidente de una declarada voluntad de aumentar el volumen de sus exportaciones agricolas a todos los mercados. Es probable que en los próximos años Estados Unidos intensifique su actividad de promoción en dos áreas geográficas, en particular: en primer lugar, en América
Latina y el Caribe, en el marco de las iniciativas aperturistas que están en curso en toda la región; en segundo lugar, en las repúblicas de la disuelta Unión Soviética, principalmente Rusia. En efecto, de los 4500 millones de dólares que, hasta este momento (Crisafulli, 1991; Marti, 1992), Estados Unidos ha prometido al conjunto de los miembros de la Mancomunidad de Estados Independientes(MFI), 3750 millones corresponden a créditos agrícolas garantizados. Paralelamente, a través de un organismo especializado - la Commodity Credit Corporation - se otorgarán otros créditos al conjunto de los ex países comunistas para permitir la compra de productos agrícolas provenientes de Estados Unidos. A través de la Commodity Credit Corporation se otorgaron alrededor de 2500 millones de dólares en 1991. Un tercer crédito de 1250 millones se acordó en noviembre de 1991. Actualmente, la MFI ya absorbe entre el 25 y el $30 \%$ de las exportaciones agrícolas de Estados Unidos; en el corto y mediano plazo, y hasta que la agricultura de las ex repúblicas soviéticas se reorganice completamente, el porcentaje de exportaciones agrícolas estadounidenses destinadas a estos mercados tendría que aumentar.

\section{IV}

\section{Las perspectivas de liberalización del comercio y los países en desarrollo}

Un desenlace exitoso de la Ronda Uruguay llevaría a la liberalización por lo menos parcial del comercio internacional de productos agrícolas. Por ahora, el espacio de maniobra de los negociadores no es muy grande, en particular si se considera la coyuntura electoral en Estados Unidos y el debate sobre la reforma de la pac en los países de la Comunidad Europea. Sin embargo, con el pasar de los meses, las perspectivas de un acuerdo de compromiso podrían hacerse más reales. Un fracaso abierto de la Ronda Uruguay tendría efectos psicológicos adversos muy fuertes en los agentes económicos, en un momento en el cual las señales de recesion mundial son ya muy serias. ${ }^{22}$

\footnotetext{
${ }^{22}$ Según una versión actualizada del Estudio económico
}

Si las negociaciones tienen resultados satisfactorios, se reforzaría la confianza general y habría un importante efecto antirrecesivo. ${ }^{23}$ Por lo demás, la Ronda Uruguay abarca demasiados sectores vitales de la economía mundial como

\footnotetext{
mundial 1991 de las Naciones Unidas, en 1991, por primera vez después de la segunda guerra mundial, se redujeron la producción y el ingreso totales del mundo.

${ }^{29}$ Como ha declarado expresamente el Director Gerente del Fondo Monetario Internacional en su discurso ante la Comisión Económica para América Latina y cl Caribe el 29 de noviembre de 1991: "Nada podría consolidar con más fuerza las perspectivas de crecimiento a mediano plazo de los paises en desarrollo, y también de los paises industriales, que la finalización exitosa de la Ronda Uruguay. Se daría con ello un espaldarazo a la confianza en el momento más necesario".
} 
para fracasar por el impasse en lo que se refiere al comercio agrícola. ${ }^{24}$

Parece importante, por lo tanto, imaginar con anticipación qué efectos tendría la liberalización del comercio agrícola internacional en las economias de los países en desarrollo.

En los últimos años se han elaborado varios modelos analíticos, algunos de alta sofisticación formal, expresamente dedicados al problema de los efectos que dicha liberalización tendría en los distintos mercados (Goldin y Knudsen, eds., 1990). El conjunto de modelos presenta escenarios múltiples con distintos grados de liberalización y con diferentes enfoques analíticos (modelos de equilibrio parcial, de equilibrio general; caso de un producto o de varios productos; mercados parciales, específicos, etc.). En general, se les ha criticado, entre otras cosas, que no hayan considerado la existencia de acuerdos comerciales preferenciales (el Acuerdo de Lomé, la Iniciativa para la Cuenca del Caribe, etc.); que no hayan prestado suficiente atención a los temas de seguridad alimentaria; que no hayan tenido en cuenta las reacciones de los países interesados en las hipótesis de variación de los precios, y que no hayan puesto de relieve las diferencias de intereses básicos entre los distintos grupos de países en desarrollo (Anania, 1990). Sin embargo, es interesante pasar revista rápida a los resultados de esos modelos, los únicos instrumentos analíticos disponibles por ahora para lograr algunas indicaciones de tendencia de los efectos que podría tener la liberalización en los mercados agrícolas.

En general, del análisis de esos resultados se desprende que los países en desarrollo serán los más condicionados, positiva o negativamente según el caso, por la liberalización del comercio agrícola. De alguna forma esto es obvio, dado que el sector agricola reviste una importancia relativa mucho mayor para los países en desarrollo que para los desarrollados.

En el corto y mediano plazo los países expor-

\footnotetext{
${ }^{24}$ Los temas negociados en la Ronda Uruguay son 14 : 1) aranceles, 2) medidas no arancelarias, 3) productos procedentes de recursos naturales, 4) textiles, 5) agricultura, 6) productos tropicales, 7) artículos del (AA $1 \%$, 8) acuerdos multilaterales, 9) medidas de salvaguardia, 10) subsidios, 11) derechos de propiedad intelectual, 12) inversiones, 13) solución de las controversias, y 14) funcionamiento del sistema CATL.
}

tadores eficientes, como los países del Grupo de Cairns, aumentarán considerablemente sus envios y sus ganancias.

Los países importadores de alimentos, por el contrario, serán afectados negativamente en el corto y mediano plazo por el alza que se prevé en los precios de muchos productos. En efecto, todos los modelos prevén que en el corto y mediano plazo los precios de las carnes, de los productos lecheros y del azúcar subirán. Todos, a excepción del modelo MTM de la ocoE (Moreddu, Parris y Huff, 1990) prevén aumentos también en los precios de los cereales para alimentación humana. En el caso de los cereales básicos para alimentación animal los resultados son más controvertidos. En efecto, tanto el modelo MTM como el modelo de Zietz y Valdés (1990) prevén una declinación en los precios como consecuencia de la crisis del sector zootécnico en los países de la ocor, crisis debida a la liberalización de los mercados. Por el contrario, los otros modelos prevén un aumento de los precios también en el sector de los cereales básicos para alimentación animal.

El examen de los modelos revela asimismo con claridad que, si junto con la liberalización de los mercados de importación de la ocor hubiera una liberalización de los mercados de exportación de los países en desarrollo, el alza en los precios sería significativamente menor ya en el mediano plazo.

En otras palabras, si las políticas de los países en desarrollo adoptaran un sesgo exportador, y si se abandonaran, por lo menos parcialmente, las medidas impositivas, cambiarias (sobrevaluación del tipo de cambio) y arancelarias (relativas a los insumos) que reducen para el productor la conveniencia de exportar, aumentarían marcadamente las posibilidades de que los agricultores de los países en desarrollo respondiesen con rapidez a las nuevas oportunidades que se crearían en los mercados internacionales como consecuencia de la liberalización en la ocos.

De esta manera, una liberalización simultánea en el Norte y en el Sur causaría un cambio progresivo en la geografía de las corrientes comerciales, junto con un aumento de la eficiencia general en lugar de un simple incremento generalizado de los precios (Krissoff, Sullivan y Wainio, 1990). Es evidente, entonces, la importancia estratégica fundamental de los mecanismos de transmisión entre precios internacionales y pre- 
cios internos en los países en desarrollo que son exportadores.

El alza de los precios internacionales, por lo tanto, sería un fuerte estímulo para la oferta agricola de los países en desarrollo. En el mediano y largo plazo se estimularía también el cambio tecnológico con aumentos consiguientes de los rendimientos. Con el tiempo, el incremento de los precios internacionales podría ser reabsorbido. Es importante que todo el proceso tenga una progresión gradual: los aumentos rápidos de los costos de los alimentos podrían tener muy graves consecuencias políticas y sociales para los países importadores, en tanto que la gradualidad del proceso podría facilitar el ajuste tanto de los paises importadores como de los exportadores.

Es preciso, de todas formas, destacar dos incógnitas que los modelos, por su misma impostación metodológica, no ayudan a resolver. En primer lugar, no está claro qué efecto agregado tendrían a mediano plazo las grandes transformaciones de la estructura de los precios internacionales, sobre la oferta agregada de China, de los países de Europa oriental y de los miembros de la ME.. Dada la magnitud de sus producciones agrícolas globales, incluso aumentos porcentuales moderados de la oferta de países como China o India podrían tener grandes efectos sobre los precios.

En segundo lugar, tampoco está claro cuál sería el impacto de las estrategias de las grandes empresas transnacionales en el mercado agroalimentario. Considerando las cuotas de mercado que controlan estas empresas, ${ }^{25}$ la hipótesis de competencia perfecta que está en la base de la gran mayoría de los modelos aparece, por lo menos para algunos productos, como poco realista. La intermediación de las grandes empresas transnacionales hace que los productores agrícolas en los paises exportadores se encuentren en muchos mercados frente a un oligopsonio, mientras que

\footnotetext{
2:3 Por ejemplo, al comienzo de los años ochenta, cinco grancies empresas controlaban alrededor del $90 \%$ de las exportatones de trigo y maiz procedentes de la Comunidad Europea, asi el $90 \%$ de las exportaciones de trigo argentinas $y$ el $90 \%$ de las exportaciones de sorgo en Australia. En la mismi época, cuatro empresas controlaban entre 60 y $65 \%$ del ner iado mundial del azúcar, y tres empresas el $60 \%$ del mercad, del cacao. Sobre estos temas véase Davies (1986), y Crarter y Heid (1983).
}

los consumidores en los países importadores son abastecidos a través de un oligopolio.

Para muchos países en desarrollo, las negociaciones específicamente dedicadas a los productos tropicales han tenido una importancia especial. Respecto de estos productos, la posición de los países desarrollados ha sido, en general, más flexible que frente a otros. El objetivo específico del grupo de negociación dentro de la Ronda Uruguay ha sido lograr la más completa liberalización del comercio de esos productos, incluso en forma elaborada y semielaborada, abarcando las medidas arancelarias y todas las medidas no arancelarias que afecten a dicho comercio. Según la Declaración de Punta del Este, este sector debería recibir especial atención, habida cuenta de la importancia que reviste el comercio de productos tropicales para muchos países en desarrollo. ${ }^{26}$

El principal logro de estas negociaciones ha sido la concesión unilateral de reducciones arancelarias por parte de varios paises desarrollados, reducciones que comenzaron a aplicarse en enero de 1989. Posteriormente se han presentado otras propuestas más incisivas, pero los países desarrollados han vinculado los resultados de las negociaciones en esta esfera con los que se alcancen en otros grupos. Además, han tendido a ser menos abiertos cuanto más alto es el grado de elaboración del producto (Anania, 1990). Esto se ha traducido en el fenómeno ya mencionado de la progresión arancelaria.

Puesto que para los paises en desarrollo es muy importante pasar de la fase del desarrollo agroexportador a la del desarrollo agroindustrial, el problema de la progresión arancelaria tiene que ser tomado con la debida consideración por todas las partes interesadas.

Un último punto que conviene destacar es el

${ }^{26}$ Si bien no hay una definición acordada de los productos tropicales, las negociaciones de este grupo se han referido a los siguientes grupos de productos: bebidas tropicales (cafe y sus productos derivados, cacao y sus productos, té y té instantáneo); especias y aceites esenciales, tlores cortadas, plantas, materias vegetales, lacas, etc., y sus productos; ciertos aceites vegetales, semillas y tortas oleaginosas; tabaco y sus productos, arroz, mandioca y otros tubérculos de plantas tropicales, y productos derivados de éstos; banano y sus productos, y otras trutas y nueces tropicales y sus productos, entre ellos el jugo de fruta: maderas tropicales y sus productos detivados, caucho natural y productos de caucho; y yute $y$ fibras duras. 
de los posibles efectos de la liberalización de los mercados agrícolas sobre las corrientes de ayuda alimentaria. La existencia de grandes excedentes en el Norte ha sido hasta ahora una condición previa importante de los planes de ayuda alimentaria dirigidos a muchos países en desarrollo. $\mathrm{Si}$ la liberalización del comercio terminara no sólo con las tendencias excedentarias de la agricultura de los países desarrollados, sino también con la ayuda alimentaria, podría haber hambre en varias regiones del mundo. Es importante, por lo tanto, reforzar y modificar oportunamente los mecanismos bilaterales $y$ multilaterales de ayuda alimentaria, para evitar emergencias inmanejables en el momento en que se hagan sentir los efectos de la liberalización.

\section{V \\ Conclusiones}

La segunda mitad de los años ochenta fue un período difícil para la agricultura de los países en desarrollo. El deterioro de las relaciones de precios del intercambio, la debilidad de los mercados para sus exportaciones de productos básicos, la carga de la deuda externa y las tensiones inflacionarias, se sumaron en varias regiones del mundo para deprimir los ingresos y los salarios y empeorar el nivel de vida de amplios sectores de la población. Fueron años en los cuales en muchos países se pidió demasiado a la agricultura. Se le pidió, de un lado, alimentar a una población que se multiplicaba y, de otro, liberar los recursos necesarios para financiar la deuda y las importaciones.

Pese a que el ritmo de crecimiento del valor de las exportaciones agropecuarias de muchos países en desarrollo se ha ido reduciendo y que, en todo caso, ha sido inferior al ritmo de expansión de las exportaciones agrícolas de los países de la ocne o de algunos países asiáticos, la agricultura se ha convertido en varios casos - particularmente en los países en desarrollo desprovistos de recursos mineros-en la fuente principal de divisas.

Cualquiera sea el desenlace de la Ronda Uruguay, los años noventa serán de intensa competencia en los mercados agrícolas internacionales. En caso de que se liberalicen los mercados de importación de la ocDE, cabe prever en un primer momento un alza de los precios de muchos productos de clima templado, entre ellos los cereales básicos para la alimentación humana. Es previsible, sin embargo, que en el largo plazo los precios bajarán nuevamente, si no hay cambios es- tructurales profundos en la composición de la demanda agrícola mundial.

En efecto, es fundamental considerar un punto clave: el problema básico del comercio agricola mundial y lo que limita fuertemente sus posibilidades de desarrollo está en la separación entre la demanda potencial y los recursos necesarios para que esa demanda potencial se transforme en demanda efectiva. Mientras los mercados de los países en desarrollo no estén en condiciones de comprar la producción agrícola que necesitan para alimentar a sus crecientes poblaciones, las posibilidades de desarrollo del comercio agrícola mundial serán siempre limitadas.

Los nuevos mercados que se van abriendo para los recursos naturales renovables ofrecen indudablemente grandes oportunidades a los países o las empresas innovadoras que - a través de nuevos productos, nuevas tecnologías de transporte o nuevas estrategias comerciales- 10 gren insertarse exitosamente y aprovechar segmentos o nichos de mercados vírgenes. Pero la experiencia regional y mundial muestra que con el paso del tiempo, entran a los mercados internacionales otros países competidores y que se van generando crisis de sobreoferta y caída de los precios. Los países industrializados tienen mercados restringidos para nuevos productos primarios renovables, y los ciclos de expansión y saturación en la actualidad son relativamente breves. Estudiar esos espacios y ciclos puede ser muy importante para las estrategias nacionales de desarrollo.

Convendría iniciar, expandir o consolidar algunas cadenas agroexportadoras, alentando por 
diversos medios su eficiencia y su competitividad, siempre que no se confundan estas opciones con la esencia de una estrategia de crecimiento y desarrollo. Diversificar la producción primaria con fines de abastecimiento interno o de exportación, salvo en situaciones muy particulares, no parece base suficiente para una estrategia de desarrollo a largo plazo, por muy promisorias que algunas cadenas agroexportadoras puedan aparecer.

Es evidente que los diversos países agroexportadores deberán perseguir el desarrollo agroindustrial, para pasar a un nivel productivo más complejo y aumentar la diversificación de las exportaciones. El desarrollo agroind ustrial favorece también la articulación interna de la economía, acelera el proceso de modernización social y productiva de las áreas rurales y conduce a la producción de bienes que tienen opción de venta en los mercados internos. Pero el desarrollo agroindustrial, aun concebido en términos más amplios, y orientado tanto al mercado interno como al mercado internacional, no puede por sí solo modificar radicalmente la situación de los países en desarrollo agroexportadores.

América Latina y el Caribe tendrán que seguir con gran atención las transformaciones que se están perfilando en los mercados mundiales de productos agrícolas, entre otras, la evolución de las agriculturas de los países de Europa oriental y las repúblicas de la ex Unión Soviética; los cambios en las economías asiáticas, que están avanzandodecididamente hacia niveles de mayor autosuficiencia alimentaria e incluso hacia la conversión de sus agriculturas en fuente importante de exportación; la evolución de las tensiones entre los grandes paises exportadores de productos agrícolas de clima templado, que se vienen canalizando por la vía de la Ronda Uruguay, y la saturación relativamente rápida que ocurre en los mercados de nuevos productos, especialmente tropicales y subtropicales, en los cuales varios países africanos y asiáticos están tratando de incursionar.

Por lo tanto, los procesos de apertura fundados principalmente en la inserción en el comercio internacional por la vía de los productos agrícolas o agroindustriales merecen un atento y prudente seguimiento.

Para concluir, cabe destacar que, en el marco de las tendencias económicas que predominan hoy, la apertura de la economía, unida a la reducción simultánea de la capacidad reguladora del Estado, podría estar creando en algunos países nuevas fuerzas concentradoras de recursos naturales renovables. La dinámica concentradora podría encauzarse a través del intercambio de deuda externa por recursos, y por la vía de la transnacionalización de la propiedad o del uso de los recursos renovables. Este fenómeno estaría reforzado por la tendencia a volver a descubrir ventajas comparativas en torno a la valorización de tales recursos.

\section{Bibliografia}

Anania, G. (1990): Liberalizzazione del commercio internazional dei prodotti agricoli e pacsi in via di sviluppo, $\mathrm{M}$. Gongoni y A. Zezza, Scarsità e sowrapproduzione nell' economia agroalimentare, Boloña, Italia.

Anderson, K. e Y. Hayami (1986): The Political Economy of Agriculural Protection. East Asia in Intemational Perspectize, Sidney.

Basile, E. (1990): Le radici del protezionismo agricolo. Un ipotesi strutturalista, G. Fabiani, Tra frotezionismo e liberalizzaziones dei mercati. Nuovi assetti internazionali in agricultura, Milán, Italia.

(1991): L'agricultura nel CATT: una lettura contrattuale, M. Gorgoni y A. Zezza, Scarsità e sovrapproduzione nell' economia agroalimentare, Boloña, Italia.

Boulard, A.M. (1990): Les èchanges de produits agricoles, Economie prospecive internationale, N" 44 , cuarto trimestre, París

CFlpi.(Comisión Económica para América Latina y el Caribe)
(1990): Estudio económico de América Latina y el Caribe. 1989, Santiago de Chile. Publicación de las Naciones Unidas, $\mathrm{N}^{\prime \prime}$ de venta s.90.11.6.2.

- (1991): Internacionalización y regionalización de la economia mundial: sus consecuencias para América Latina ( $\mathrm{L} / \mathrm{L}$. 644), Santiago de Chile.

Cramer, G.L. y W. G. Heid (1983): Grain Marketing Economics, Nueva York, John Wiley \& Sons, Inc.

Crisafulli, P. (1991): U.S. may boost grain credits to Soviet Union, The Journal of Commerce, 28 de octubre.

Davies, S. (1986): The grain trading companies, N. Butler, The International Grain Trade: Problems and Prospects, Royal lnstitute of International Affairs, Reino Unido.

FAO(Organización de las Naciones Unidas para la Agricultura y la Alimentación) (1990a): Anuario de Comercio, 1989, Roma.

(1990b): Situación y perspectivas de los productos básicos, 1989-90, Roma . 
(1990c): El estado mundial de la agricultura y la abmentación, 1990, Roma.

FNLAPr (Fondo de Población de tas Naciones Unidas) (1991): Estado de la población mundial, 1991 , Nueva York.

Fottorino, E. (199]): Agricultura: el talón de Aquiles de la Perestroika, Ceres, Santiago de Chile, rao, marzo-abril.

GATr (Acuerdo General sobre Aranceles Aduaneros y Comercio) (1989): El comercio intemacional 88-89, vol. II, Ginebra.

Goldin I. y O. Knudsen (eds.) (1990): Agriculural Trade Liberalization. Implications for Developing Conntries, Organización de Cooperación y Desarrollo Económicos (oc:DE)/Banco Mundial, París

Gorgoni M. y A. Zezza (1990): Scarsitá e sojmapproduzionte nell economia agroalimentare, Bolona, Italia.

Hathaway D.E. (1987): Agricuthre and the (ATT: Rerriting the Rules, Washington, D.C.

Jones, K. (1989): Voluntary export restraint: politicat economy, history and the role of the cinl", Joumal of World Trade, vol. 23, N" 3, Ginebra, Werner Publishing Company Ltd., junio.

Krissoff, B., J. Sullivan y J. Wainio (1990): Developing countries in an open economy: the case of agriculture, I.
Goldin y O. Knudsen (eds.), Agricultual Trade Liberalization. Implications for Deneloping Countres, ocos/Banco Mundial, Paris.

Marti, S. (1992): Les milieux agricoles americaines trouvent que l'effort des Etats Unis en faveur de la cel est encore très insuffisant, Le Monde, París, 21 de enero.

Mine, R.C., K.A. Ingersent y A.J. Rayner (1989): Agriculture in the Uruguay Round: From the Punta del Este declaration to the Genera Accord, Jounal of Agricultural Econonics, octubre.

Moreddu, C., K. Parris y B. Huff (1990): Agricultural policies in developing countries and agricultural trade, I. Goldin y O. Knudsen (eds.), Agricultural Trade Liberalization. Implications for Doveloping Countries, ocols/Banco Mundial, París.

Naciones L'nidas (199(1): Estadio eronimico mandial 1990, Nueva York. Publicación de las Naciones Unidas, N" de venta s.90).e1.r..1.

Zietz, J. y A. Valctés (1990); International interactions in food and agricultural policies: effects of alternative policies, 1. Goldin y O. Knudsen (eds.), Agricultural Trade Liberalization. Implications for Developing Countries, Oc:DE/Banco Mundial. París. 